\title{
A postponement model for multi-item replenishment decision considering overtime, commonality, and quality reassurance
}

\author{
Yuan-Shyi Peter Chiu ${ }^{\mathrm{a}}$, Victoria Chiu ${ }^{\mathrm{b}}$, Yunsen Wang ${ }^{\mathrm{c}, \mathrm{d}}$ and Ming-Hon Hwang ${ }^{\mathrm{e}}$
}

${ }^{a}$ Department of Industrial Engineering \& Management, Chaoyang University of Technology, Taichung 413, Taiwan

${ }^{b}$ Department of Accounting, Finance and Law, The State University of New York, Oswego, NY 13126, USA

'School of Accounting, Southwestern University of Finance \& Economics, Chengdu, 611130, China

${ }^{d}$ Department of Accounting \& Information Systems., Rutgers Business School, Newark, NJ 07102, USA

${ }^{e}$ Department of Marketing \& Logistics Management, Chaoyang University of Technology, Taichung 413, Taiwan

\section{H R O N I C L E ABS T R A C T}

Article history:

Received May 232019

Received in Revised Format

May 232020

Accepted June 42020

Available online

June 242020

Keywords:

Multiproduct replenishment

decision

Postponement

Overtime

Product quality reassurance

Commonality

Common cycle time

\begin{abstract}
This study develops a postponement model for the multi-item replenishment decision featuring commonality, an overtime strategy, and product quality reassurance. A single machine is used to meet the steady demand for multiple products wherein product commonality exists among these end products. The proposed postponement model assumes that all pertinent common parts are fabricated in Stage 1 and the finished products are sequentially fabricated in Stage 2. Random nonconformance rates are associated with both fabrication stages, the repairable nonconforming common parts are separated from scrap, and reworking in each cycle helps ensure product quality for each completed batch. An overtime strategy is used to reduce the lengthy fabrication and rework times for common parts. Mathematical analyses and derivation allow us to obtain the total system costs. The optimization method helps find the optimal replenishment decision. We provide a numerical illustration to show (1) how our model works; (2) the individual impact of the system features (e.g., the overtime factor, commonality in terms of the common part completion rate and its relative value, and the issues pertaining to scrap/rework) on the optimal decision, utilization, and the total system cost; and (3) the collective influence of system features on the highlighted problem. This proposed decision-support model helps production managers achieve the operating goals of lowering total system expenses and cutting the length of the production cycle.
\end{abstract}

\section{Introduction}

This study develops a postponement model for the multi-item replenishment decision featuring commonality, an overtime strategy, and product quality reassurance. Facing highly turbulent world markets, to stay competitive today, manufacturing firms must seek all possible ways to meet the demand of multiproduct in a timely matter, increase utilization, keep the high quality of their products, and minimize the total fabrication costs. In the production planning phase, when product commonality exists among multiple products, a postponement model is often considered to delay differentiation by first fabricating all pertinent common parts in Stage 1 and then making the finished products sequentially in Stage 2. Zinn (1990) developed distinct heuristics to help identify the potential opportunities of postponement and estimate savings of safety stock of postponement. The author indicated that savings can be derived from the connection of sales among products in a firm's product line and the magnitude

* Corresponding author Tel.\#: +886 4-23323000 (ext.5205)

E-mail: hwangmh@cyut.edu.tw (M.-H. Hwang)

2020 Growing Science Ltd.

doi: $10.5267 /$ j.. jiec.2020.6.001 
and number of products in the product line. A real example illustrated the application of these heuristics to support the research findings. Van Mieghem and Dada (1999) built a two-stage decision scheme to conduct a comparative analysis of postponement strategies to facilitate the company's decision makings on fabrication/inventory quantity, capacity investment, and price. The authors exposed the correlations of uncertainty, competition, operational decision timing impact the company's decision on strategic investment and value. Ko and $\mathrm{Hu}$ (2008) studied workload balance and machine-task assignment problem for a mixed-model fabrication under complicated asymmetric configurations. The authors used the technique of binary integer programming consisted of constraint relationships of (i) parallel/serial fabrication among tasks and (ii) task precedence and configurations. Besides, they proposed mathematical representations for the relationship of tasks and configurations. The authors further extended the problem from workload balance to the line balancing to help decide an appropriate configuration alternative for the task-machine assignment in the asymmetric fabrication environments. Ferreira et al. (2015) presented a model to explore the concept of postponement according to its implementing processes, drivers, and measures of performance. The authors employed both the theoretical- conceptual and qualitative approaches that emphasized on the review of existing articles related to the postponement strategy published from 1950 to 2012. As a result, the authors created a theoretical framework to specify the variables and procedures required to carry out the postponement strategy. Additional works (Reimann, 2012; Oladapo et al., 2017; Ahranjani and Matin, 2018; Chiu et al., 2018a, 2019a; Sheikh et al., 2019) studied diverse characteristics of the delay differentiation impact on the manufacturing firms' fabrication planning and tangible benefits.

To achieve shortening completion time of batch production, production planners often consider implementing the overtime strategy. Akkan (1996) proposed an overtime scheduling approach for a capacitated real-time planning and scheduling system, to optimally select the work-centers to not only meet the demand due time but also keep the overtime cost minimum. The author used a work-order insertion method to schedule a new work-order without affecting the sequence of original work-orders. The performances of several heuristics were examined according to this approach. Lagodimos and Mihiotis (2006) examined the planning decision on the overtime versus regular shifts in the packaging stage of manufacturing firms. The authors aimed to plan manpower and overtime routinely for every workday's shifts to meet the production requirement as well as keep the overtime cost at a minimum. An integer linear programming model was constructed to find the optimal policy via a commercial integer linear programming optimizer. Their results indicated that through effective overtime usage, significant reductions on workforce and utilization can be achieved. Freeman et al. (2015) studied a scheduling problem for a parallel (non-identical) machines system to minimize the waste and overtime costs. The studied systems are subject to sequence-dependent set-up times and costs, so the feasible equipment assignments lead to minimal production time and waste. The authors employed the mixed integer programming techniques in their solution procedures to leverage the overtime manpower and waste costs for the large-size problems and used an algorithm to decide the initial product/machine assignments. Then, the decomposition heuristic was utilized to solve the relaxed sub-problem. Through various experiments the authors demonstrated that their approach outperformed conventional methods in terms of minimizing the overtime manpower and waste costs. Additional works (Van Mieghem, 1999; Jirjahn, 2008; MohanDas, 2017; Chiu et al., 2018b,c, 2019b; Palos-Sanchez et al., 2019; Taş et al., 2019) investigated diverse characteristics of overtime strategies effect on enterprises' fabrication planning, operation management, and operating costs.

In a real manufacturing environment, it is inevitable to have a random nonconformance rate associated with a fabrication process. To identify and rework the repairable items and remove the scraps can reensure the quality of a finished batch. Alfredsson (1997) built a mathematical model to determine the required quantity of spares/test equipment for a support system to ensure the operation satisfactory and cost minimization of a fleet of technical systems. Yu and Efstathiou (2006) explored the complexity of manufacturing systems containing rework cells. Various types of rework cells were defined with diverse sets of parameters, and the quantitative analyses were conducted. The resulting complexity metric helped 
measure/identify the dissimilarity among the alternative rework cells in terms of complexity, quality, and cost, to facilitate a better design decision of the rework cells. Roul et al. (2015) examined an imperfect multiproduct fabrication system featuring dynamic product requirements over a finite period of time and variable fabrication rate in different periods. Their study assumed that defective products can be partially reworked and repaired, the unit fabrication cost is related to its production rate, and a budget constraint is associated with the total fabrication-inventory costs of the system. The authors formulated and treated the system as an optimal control problem to maximize total profit and meeting product quality spec. Several methods including Hamiltonian, Kuhn-Tucker, etc. were employed to help resolve the studied problem and numerical illustrations revealed some characteristics of the problem to facilitate managerial decision makings. Additional works (Khanna et al., 2017; Abashar, 2018; Aringhieri et al., 2018; Pearce et al., 2018; Rao \& Singh, 2018; Iqbal et al., 2019; Istotskiy \& Protasev, 2019; Larkin \& Privalov, 2019; Noman et al., 2019; Omar et al., 2019; Ortiz-Servin et al., 2019; Parnianifard et al., 2019; Wenbin et al., 2019) investigated the impact of diverse characteristics of imperfect fabrication/ products and their consequence actions on the production-inventory costs and operations management/planning. Due to little prior study explicitly concentrated on the investigation of the collective influence of the delayed differentiation policy with overtime strategy implemented on the fabrication of the common parts, and product quality reassurance, this work aims to fill the gap.

\section{Nomenclature}

$L=$ the number of distinct end products needs to be manufactured,

$T_{\mathrm{A}}=$ the common manufacturing cycle length - the decision variable,

$\lambda_{i} \quad=$ demand rate of the end product $i$ (where $i=1,2, \ldots, L$ ),

$Q_{i} \quad=$ the lot size of end product $i$,

$t_{1, i}=$ manufacturing uptime of end product $i$ in stage 2 ,

$t_{2, i}=$ rework time of nonconforming end product $i$,

$t_{3, i}=$ depletion time of end product $i$,

$t_{i}^{*}=$ summation of optimal uptimes of end products in stage two,

$K_{i} \quad=$ setup cost for end product $i$,

$C_{i}=$ unit manufacturing cost for end product $i$,

$h_{1, i}=$ unit holding cost for end product $i$,

$h_{2, i}=$ unit holding cost for reworked end product $i$ in $t_{2, i}$,

$h_{4, i}=$ unit holding cost for the safety end product $i$,

$S_{i} \quad=$ setup time for end product $i$,

$P_{1, i}=$ annual manufacturing rate for end product $i$,

$x_{i}=$ random nonconforming percentage in the manufacturing process of end product $i$,

$\theta_{1, i}=$ the scrap percentage of the nonconforming end product $i$,

$C_{\mathrm{S}, i}=$ unit disposal cost for scrapped product $i$,

$d_{1, i}=$ production rate of nonconforming end product $i$ (i.e., $d_{1, i}=x_{i} P_{1, i}$ ),

$P_{2, i}=$ annual reworking rate for end product $i$,

$C_{\mathrm{R}, i}=$ unit rework cost for end product $i$,

$\theta_{2, i}=$ the scrap percentage of the reworked end product $i$,

$d_{2, i}=$ production rate of scrap product $i$ in $t_{2, i}$ (i.e., $\left.d_{2, i}=\theta_{2, i} P_{2, i}\right)$,

$\varphi_{i} \quad=$ total scrap percentages during manufacturing of end product $i$,

$H_{1, i}=$ the inventory status of end product $i$ when its uptime ends,

$H_{2, i}=$ the inventory status of end product $i$ when its rework time ends,

$Q_{0} \quad=$ the manufacturing lot size of common parts in stage 1,

$\lambda_{0}=$ the common parts' annual demand rate,

$P_{\mathrm{T} 1,0}=$ annual manufacturing rate of common parts when overtime option is implemented,

$P_{1,0}=$ standard annual manufacturing rate of common part (without overtime option),

$\alpha_{1,0}=$ the linking parameter between $P_{\mathrm{T} 1,0}$ and $P_{1,0}$,

$K_{\mathrm{T} 0}=$ the setup cost of common part's manufacturing process with overtime option,

$K_{0}=$ common part's standard setup cost, 
$\alpha_{2,0}=$ the linking parameter between $K_{\mathrm{T} 0}$ and $K_{0}$,

$C_{\mathrm{T} 0}=$ unit manufacturing cost of common part with overtime option,

$C_{0}=$ common part's standard unit manufacturing cost,

$\alpha_{3,0}=$ the linking parameter between $C_{\mathrm{T} 0}$ and $C_{0}$,

$h_{1,0}=$ common part's unit holding cost,

$t_{1,0}=$ the manufacturing uptime of common parts when the overtime is implemented,

$t_{2,0}=$ the reworking time of the nonconforming common parts,

$t_{3,0}=$ the depletion time of the common parts,

$\gamma=$ the common part's completion rate as compared with the finished product,

$t_{0}{ }^{*}=$ the optimal sum of uptime and rework time (i.e., $\left.\left(t^{*}{ }_{1,0}+t^{*}{ }_{2,0}\right)\right)$ in stage one,

$t_{\mathrm{i}}^{*}=$ the optimal sum of uptime and rework times (i.e., $\left.\Sigma_{\mathrm{i}}\left(t^{*}{ }_{1, \mathrm{i}}+t_{2, \mathrm{i}}^{*}\right)\right)$ in stage two,

$H_{1,0}=$ the inventory status of common parts when its uptime ends,

$H_{2,0}=$ the inventory status of common parts when its rework time ends,

$x_{0}=$ random nonconforming percentage in the manufacturing process of common parts,

$d_{\mathrm{T} 1,0}=$ the manufacturing rate of nonconforming common parts, thus, $d_{\mathrm{T} 1,0}=x_{0} P_{\mathrm{T} 1,0}$,

$\theta_{1,0}=$ the scrap portion of the nonconforming common parts in $t_{1,0}$,

$C_{\mathrm{S}, 0}=$ unit disposal cost for scrap common part,

$P_{\mathrm{T} 2,0}=$ annual reworking rate of common parts with overtime option implemented in $t_{2,0}$,

$P_{2,0}=$ standard annual reworking rate of nonconforming common part (without overtime option),

$C_{\mathrm{TR}, 0}=$ common part's unit rework cost with overtime option implemented in $t_{2,0}$,

$C_{\mathrm{R}, 0}=$ common part's standard unit rework cost (without overtime option in $t_{2,0}$ ),

$\theta_{2,0}=$ the scrap portion of the reworked common parts in $t_{2,0}$,

$d_{\mathrm{T} 2,0}=$ the manufacturing rate of scrap common parts in $t_{2,0}$, thus, $d_{\mathrm{T} 2,0}=\theta_{2,0} P_{\mathrm{T} 2,0}$,

$\varphi_{0}=$ overall scrap rate of common parts in stage one,

$h_{2,0}=$ unit holding cost for the reworked common parts in $t_{2,0}$,

$h_{4,0}=$ unit holding cost for the safety common part,

$i_{0}=$ the inventory holding cost relating ratio (i.e., $\left.h_{1, i}=\left(i_{0}\right) C_{i}\right)$,

$H_{i} \quad=$ the inventory status of common parts when the uptime of fabrication process of product $i$ ends,

$S_{0}=$ common part's setup time in stage 1 ,

$I(t)_{i}=$ the inventory status at time $t$ of product $i$ (where $i=0,1,2, \ldots, L$ ),

$E\left[T_{\mathrm{A}}\right]=$ the expected common manufacturing cycle time,

$T C\left(T_{\mathrm{A}}\right)=$ total system cost in a manufacturing cycle,

$E\left[T C\left(T_{\mathrm{A}}\right)\right]=$ the expected total system cost in a manufacturing cycle,

$E\left[\operatorname{TCU}\left(T_{\mathrm{A}}\right)\right]=$ the expected system cost per unit time.

\section{Model description and formulation}

A postponement model for multi-item replenishment decision considering overtime, commonality, and quality reassurances is investigated. The feature and assumption of the model are described as follows: (1) A delayed differentiation strategy is implemented in this multi-item postponement model considering overtime, commonality, and quality reassurances, where common parts are manufactured in the first stage and finished items are manufactured in sequence in the second stage. (2) The common part's completion percentage $\gamma$ (as compared with the end product) is a known constant and its manufacturing rate $P_{1,0}$ depends on $\gamma$. (3) an overtime option is implemented in stage one of this postponement model to increase its annual manufacturing rate to $P_{\mathrm{T} 1,0}$, thus, reduce its uptime. The relationship between $P_{\mathrm{T} 1,0}$ and $P_{1,0}$ is shown in Eq. (1), and its consequent relationships of cost-relevant parameters are exhibited in Eqs. (2) and (3). (4) The demand rate $\lambda_{i}$ of $L$ end items is constant (where $i=1,2, \ldots, L$ ). (5) The manufacturing rate $P_{1, i}$ for end product $i$ also depends on $\gamma$, e.g., if $\gamma=50 \%$, then both $P_{1,0} P_{1, i}$ are twice as much as its standard rate in a single-stage manufacturing system. (6) random nonconforming percentage $x_{0}$ and $x_{i}$ occur in both manufacturing stages, also a $\theta_{1,0}$ portion (in stage 1 ) and a $\theta_{1, i}$ portion (in stage 2 ) among the nonconformance items are detected as scrap, and the others are reworked at the annual rate of $P_{\mathrm{T} 2,0}$ (which is also associated with overtime plan) and $P_{2, i}$, respectively. During the rework processes, a $\theta_{2,0}$ portion (in stage 1) and a $\theta_{2, i}$ portion (in stage 2 ) of the reworked items fail and are classified as scrap. 
(7) The relationship between $P_{\mathrm{T} 2,0}$ and $P_{2,0}$ is displayed in Eq. (4), and its consequent relationship of costrelevant parameters is shown in Eq. (5). Inventory status of this postponement model for a multi-item replenishment system with overtime, commonality, and quality reassurance is shown in Fig. 1.

$$
\begin{aligned}
& P_{\mathrm{T} 1,0}=\left(1+\alpha_{1,0}\right) P_{1,0} \\
& K_{\mathrm{T} 0}=\left(1+\alpha_{2,0}\right) K_{0} \\
& C_{\mathrm{T} 0}=\left(1+\alpha_{3,0}\right) C_{0} \\
& P_{\mathrm{T} 2,0}=\left(1+\alpha_{1,0}\right) P_{2,0} \\
& C_{\mathrm{TR}, 0}=\left(1+\alpha_{3,0}\right) C_{\mathrm{R}, 0}
\end{aligned}
$$

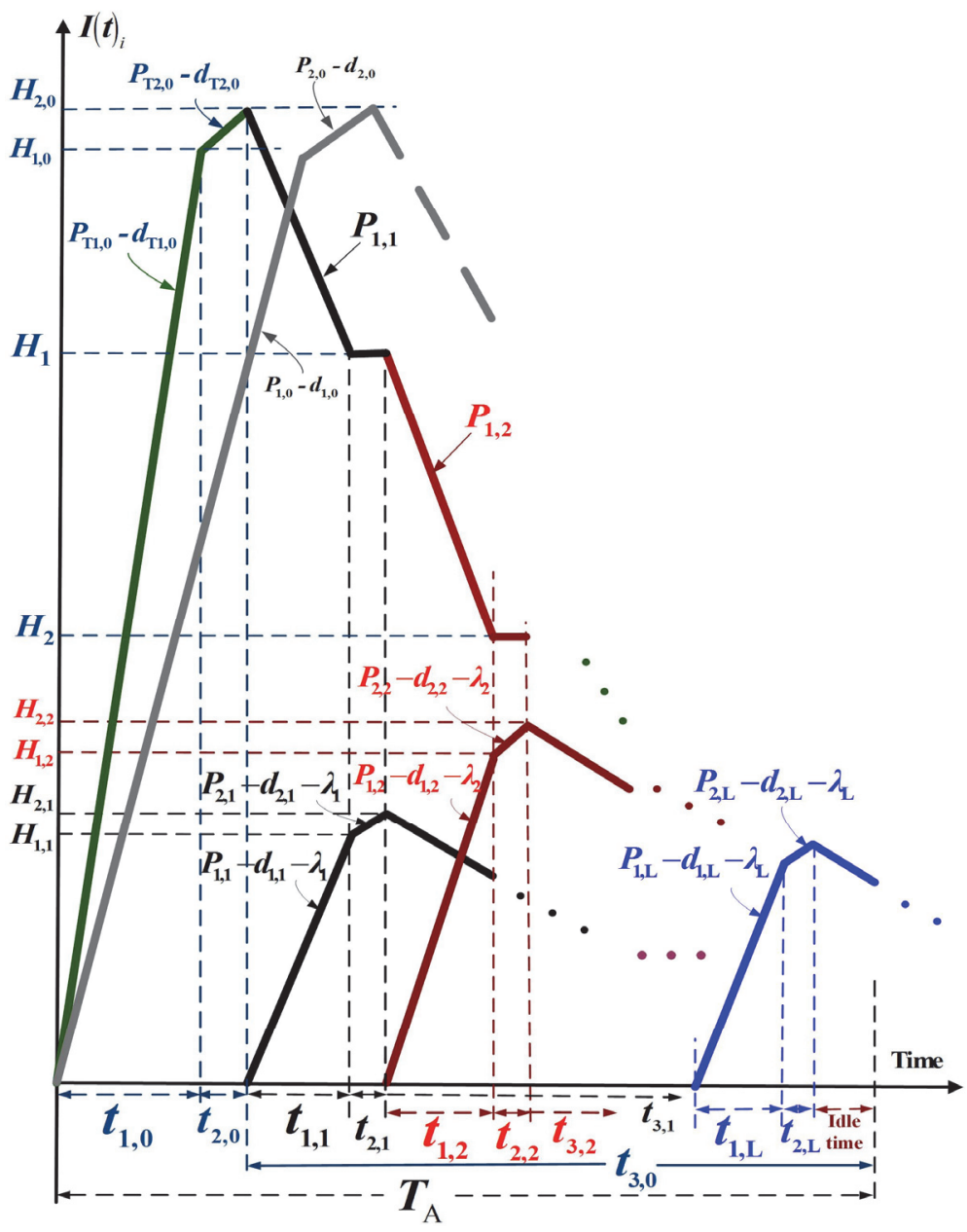

Fig. 1. The inventory status of the proposed postponement model with overtime, commonality, and quality assurance as compared with the same system without overtime option (in grey)

It shows that in stage one, the common part's stock level piles up to $H_{1,0}$ when its uptime (i.e., $\left.t_{1,0}\right)$ ends, and it reaches $H_{2,0}$ when its rework time (i.e., $t_{2,0}$ ) completes. Then, in stage two (see $t_{3,0}$ in Fig. 1 ), the common part's inventory level starts to decline as the manufacturing processes of end products begin. Fig. 2 depicts the separate common part's stock status during the manufacturing processes of each finished item $i$. Meantime, for each end-product $i$ (where $i=1,2, \ldots, L$ ), the stock level piles up to $H_{1, i}$ at the end of its uptime (refer to Fig. 1) and the stock level reaches $H_{2, i}$ when its rework time completes. 


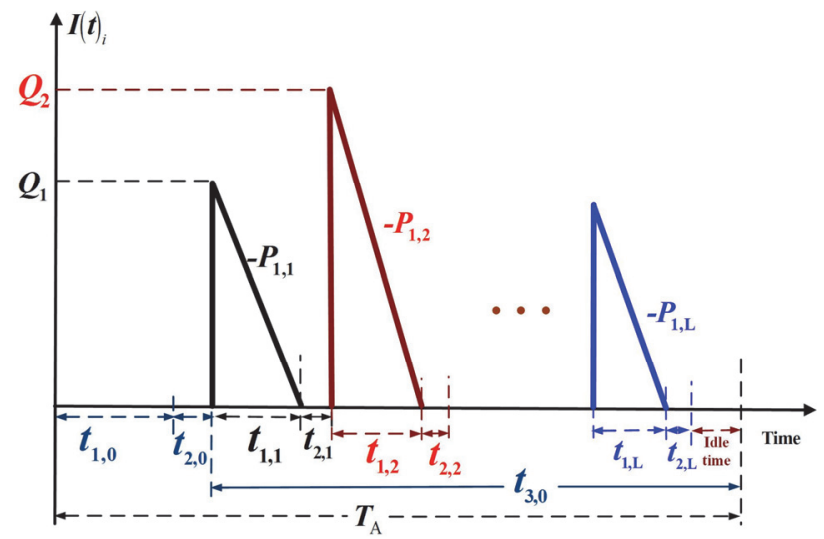

Fig. 2. The separate common part's stock status during the manufacturing process of each end product $i$.

No shortages are permitted, thus in stage $1, P_{\mathrm{T} 1,0}-d_{\mathrm{T} 1,0}$ must be greater than zero and in stage two, $P_{1, i}-$ $d_{1, i}-\lambda_{i}$ must be greater than zero too. Fig. 3 demonstrates the inventory level of nonconforming items in this multi-item postponement model. It specifies the nonconforming common parts reaches $\left(d_{T 1,0} t_{1,0}\right)$ when the uptime $t_{1,0}$ ends and upon removal of the scrap, the rework process gradually brings nonconforming common part's stock level down, and it reaches zero when the rework time $t_{2,0}$ ends. Similar situations happen in stage 2 for each end product $i$ (refer to the stock status during $t_{3,0}$ ).

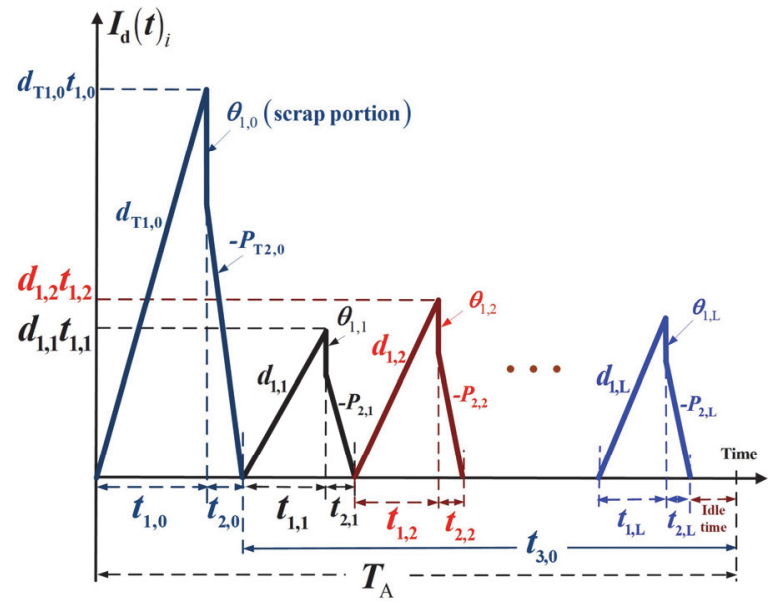

Fig. 3. The inventory level of nonconforming items of this multi-item postponement model

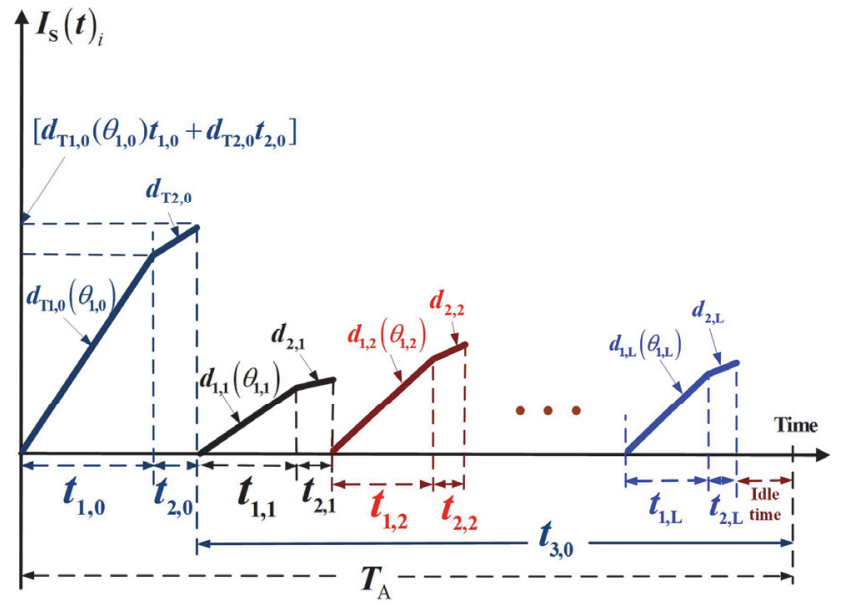

Fig. 4. The scrap stock status of this multi-item postponement model

The inventory level of scrap items of this multi-item postponement model is exhibited in Fig. 4. It indicates that in stage one, the maximal level of scrap common parts piles up to $\left[d_{\mathrm{T} 1,0}\left(\theta_{1,0}\right) t_{1,0}+d_{\mathrm{T} 2,0} t_{2,0}\right]$ when the rework time $t_{2,0}$ ends and in stage two, the maximal level of each scrap end product $i$ reaches $\left[d_{1, i}\left(\theta_{1, i}\right) t_{1, i}+d_{2, i} t_{2, i}\right]$.

\subsection{The formulation for stage two - when end products are manufactured}

According to the problem's description and assumption, along with observations of Fig. 1 to Fig. 4 , the following formulas are gained for $i=1,2, \ldots, L$ :

$$
\begin{aligned}
T_{\mathrm{A}} & =t_{1, i}+t_{2, i}+t_{3, i}=\frac{Q_{i}\left(1-x_{i} \varphi_{i}\right)}{\lambda_{i}} \\
Q_{i} & =\frac{\lambda_{i} T_{\mathrm{A}}}{1-\varphi_{i} x_{i}}
\end{aligned}
$$




$$
\begin{aligned}
& t_{1, i}=\frac{Q_{i}}{P_{1, i}}=\frac{H_{1, i}}{P_{1, i}-d_{1, i}-\lambda_{i}} \\
& t_{2, i}=\frac{x Q_{i}}{P_{2, i}}=\frac{H_{2, i}-H_{1, i}}{P_{2, i}-d_{2, i}-\lambda_{i}} \\
& H_{1, i}=\left(P_{1, i}-d_{1, i}-\lambda_{i}\right) t_{1, i} \\
& H_{2, i}=H_{1, i}+\left(P_{2, i}-d_{2, i}-\lambda_{i}\right) t_{2, i} \\
& t_{3, i}=\frac{H_{2, i}}{\lambda_{i}} \\
& \varphi_{i}=\theta_{1, i}+\left(1-\theta_{1, i}\right) \theta_{2, i}
\end{aligned}
$$

Based on Eq. (7), the requirement of common parts at the end of stage 1 should be as follows:

$$
H_{2,0}=\sum_{i=1}^{L} Q_{i}=\sum_{i=1}^{L} \frac{\lambda_{i} T_{\mathrm{A}}}{1-\varphi_{i} x_{i}}
$$

\subsection{The formulation for stage one-when common parts are manufactured}

According to the problem's description and assumption, along with observations of Figs 1 to Fig. 4, the following formulas are gained:

$$
\begin{aligned}
& \sum_{i=1}^{L} Q_{i} \\
& \lambda_{0} \\
& H_{2,0}=\left(\sum_{i=1}^{L} Q_{i}\right) \\
& Q_{0}=\frac{H_{2,0}}{1-\varphi_{0} x_{0}} \\
& t_{1,0}=\frac{Q_{0}}{P_{T 1,0}}=\frac{H_{1,0}}{P_{T 1,0}-d_{T 1,0}} \\
& t_{2,0}=\frac{Q_{0}\left[x_{0}\left(1-\theta_{1,0}\right)\right]}{P_{\mathrm{T} 2,0}}=\frac{H_{2,0}-H_{1,0}}{P_{\mathrm{T} 2,0}-d_{\mathrm{T} 2,0}} \\
& H_{1,0}=\left(P_{T 1,0}-d_{T 1,0}\right) t_{1,0} \\
& H_{2,0}=H_{1,0}+\left(P_{\mathrm{T} 2,0}-d_{\mathrm{T} 2,0}\right) t_{2,0} \\
& \varphi_{0}=\theta_{1,0}+\left(1-\theta_{1,0}\right) \theta_{2,0} \\
& T_{\mathrm{A}}=t_{1,0}+t_{2,0}+t_{3,0} \\
& H_{1}=H_{2,0}-Q_{1} \\
& H_{i}=H_{(i-1)}-Q_{i}, \text { for } i=2,3, \ldots, L \\
& H_{L}=H_{(L-1)}-Q_{L}=0
\end{aligned}
$$

\section{Cost analysis and solution}

\subsection{Cost analysis}

$T C\left(T_{\mathrm{A}}\right)$, the total system cost in a manufacturing cycle comprises the following costs incurred in both 
stages: (1) for stage one: manufacturing variable, setup, rework, disposal, and inventory holding costs; and (2) for stage two: summation of manufacturing variable, setup, rework, disposal, and stock holding costs for $L$ different end products. Hence, $T C\left(T_{\mathrm{A}}\right)$ is

$$
\begin{aligned}
& T C\left(T_{\mathrm{A}}\right)=K_{T 0}+C_{T 0} Q_{0}+C_{S, 0}\left(x_{0} \varphi_{0} Q_{0}\right)+C_{T R, 0}\left[x_{0}\left(1-\theta_{1,0}\right) Q_{0}\right]+h_{2,0}\left(\frac{d_{T 1,0} t_{1,0}\left(1-\theta_{1,0}\right)}{2}\right)\left(t_{2,0}\right) \\
& +h_{1,0}\left[\frac{H_{1,0} t_{1,0}}{2}+\frac{H_{2,0}+H_{1,0}}{2}\left(t_{2,0}\right)+\frac{d_{T 1,0} t_{1,0}}{2}\left(t_{1,0}\right)+\sum_{i=1}^{L}\left[\frac{Q_{i}}{2}\left(t_{1, i}\right)+H_{i}\left(t_{1, i}+t_{2, i}\right)\right]\right] \\
& +\sum_{i=1}^{L}\left\{\begin{array}{l}
C_{i} Q_{i}+K_{i}+C_{R, i}\left[x_{i}\left(1-\theta_{1, i}\right) Q_{i}\right]+C_{S, i}\left(x_{i} \varphi_{i} Q_{i}\right)+h_{2, i}\left(\frac{d_{1, i} t_{1, i}\left(1-\theta_{1, i}\right)}{2}\right)\left(t_{2, i}\right) \\
+h_{1, i}\left[\frac{H_{1, i} t_{1, i}}{2}+\frac{H_{2, i}+H_{1, i}}{2}\left(t_{2, i}\right)+\frac{H_{2, i}}{2}\left(t_{3, i}\right)+\frac{d_{1, i} t_{1, i}}{2}\left(t_{1, i}\right)\right]+h_{4, i}\left(x_{i} \varphi_{i} Q_{i}\right) T_{\mathrm{A}}
\end{array}\right\}+h_{4,0}\left(x_{0} \varphi_{0} Q_{0}\right) T_{\mathrm{A}}
\end{aligned}
$$

$E\left[T C U\left(T_{\mathrm{A}}\right)\right]$ can be obtained after extra derivation efforts (see Appendix A for details) as follows:

$$
\begin{aligned}
E\left[T C U\left(T_{\mathrm{A}}\right)\right]=\left\{\begin{array}{l}
\frac{\left[\left(1+\alpha_{2,0}\right) K_{0}\right]}{T_{A}}+\left[\left(1+\alpha_{3,0}\right) C_{0}\right] \lambda_{0} E_{00}+\left[\left(1+\alpha_{3,0}\right) C_{R}\right] \lambda_{0}\left(1-\theta_{1,0}\right) E_{10} \\
+C_{\mathrm{S}, 0} \varphi_{0} \lambda_{0} E_{10}+\left(\frac{h_{2,0}}{2}\right)\left\{\frac{T_{A}\left[\lambda_{0}\left(1-\theta_{1,0}\right)\right]^{2}}{\left(1+\alpha_{1,0}\right) P_{2,0}}\right\} E_{10}{ }^{2}+\left(\frac{h_{1,0}}{2}\right)\left(T_{A} \lambda_{0}^{2}\right) E_{0 P} E_{00}{ }^{2} \\
+h_{1,0} \sum_{i=1}^{L}\left\{\frac{\lambda_{i}^{2} T_{A}}{2 P_{1, i}} E_{0 i}{ }^{2}\right\}+h_{1,0} \sum_{i=1}^{L}\left[\frac{\lambda_{i} T_{A}}{P_{1, i}} E_{0 i} \sum_{i=1}^{L} \lambda_{i} E_{0 i}+\frac{\lambda_{i} T_{A}\left(1-\theta_{1, i}\right)}{P_{2, i}} E_{1 i} \sum_{i=1}^{L} \lambda_{i} E_{0 i}\right] \\
+h_{4,0} \varphi_{0} \lambda_{0} T_{A} E_{10}+h_{1,0} \sum_{i=1}^{L}\left[-\frac{\lambda_{i} T_{A}}{P_{1, i}} E_{0 i} \sum_{j=1}^{i} \lambda_{j} E_{0, j}-\frac{\lambda_{i} T_{A}\left(1-\theta_{1, i}\right)}{P_{2, i}} E_{1 i} \sum_{j=1}^{i} \lambda_{j} E_{0 j}\right]
\end{array}\right\} \\
+\sum_{i=1}^{L}\left\{\begin{array}{l}
C_{i} \lambda_{i}\left(E_{0 i}\right)+\frac{K_{i}}{T_{A}}+C_{R, i} \lambda_{i}\left(1-\theta_{1, i}\right)\left(E_{1 i}\right)+C_{\mathrm{S}, i} \lambda_{i} \varphi_{i}\left(E_{1 i}\right) \\
+\frac{h_{2, i} \lambda_{i}^{2} T_{A}}{2}\left(E_{1 i}\right)^{2}\left[\frac{\left(1-\theta_{1, i}\right)^{2}}{P_{2, i}}\right]+h_{4, i} \varphi_{i} \lambda_{i} T_{A}\left(E_{1 i}\right)+\frac{h_{1, i} \lambda_{i}^{2} T_{A}}{2}\left(E_{0 i}\right)^{2} E_{i P}
\end{array}\right\}
\end{aligned}
$$

\subsection{The optimal common manufacturing cycle length solution}

By applying the $1^{\text {st }}$ and $2^{\text {nd }}$ derivatives of $E\left[T C U\left(T_{\mathrm{A}}\right)\right]$, the following are gained:

$$
\begin{aligned}
& \frac{d E\left[T C U\left(T_{\mathrm{A}}\right)\right]}{d T_{\mathrm{A}}}=\left\{\begin{array}{l}
-\frac{\left[\left(1+\alpha_{2,0}\right) K_{0}\right]}{T_{A}{ }^{2}}+\left(\frac{h_{2,0}}{2}\right)\left\{\frac{\left[\lambda_{0}\left(1-\theta_{1,0}\right)\right]^{2}}{\left(1+\alpha_{1,0}\right) P_{2,0}}\right\} E_{10}{ }^{2}+\left(\frac{h_{1,0}}{2}\right)\left(\lambda_{0}\right)^{2} E_{0 P} E_{00}{ }^{2} \\
+h_{1,0} \sum_{i=1}^{L}\left\{\frac{\lambda_{i}{ }^{2}}{2 P_{1, \mathrm{i}}} E_{0 i}{ }^{2}\right\}+h_{1,0} \sum_{i=1}^{L}\left[\frac{\lambda_{i}}{P_{1, \mathrm{i}}} E_{0 i} \sum_{i=1}^{L} \lambda_{i} E_{0 i}+\frac{\lambda_{i}\left(1-\theta_{1, i}\right)}{P_{2, i}} E_{1 i} \sum_{i=1}^{L} \lambda_{i} E_{0 i}\right] \\
+h_{4,0} \varphi_{0} \lambda_{0} E_{10}+h_{1,0} \sum_{i=1}^{L}\left[-\frac{\lambda_{i}}{P_{1, i}} E_{0 i} \sum_{j=1}^{i} \lambda_{j} E_{0 j}-\frac{\lambda_{i}\left(1-\theta_{1, i}\right)}{P_{2, i}} E_{1 i} \sum_{j=1}^{i} \lambda_{j} E_{0 j}\right]
\end{array}\right\} \\
& +\sum_{i=1}^{L}\left\{-\frac{K_{i}}{T_{A}{ }^{2}}+\frac{h_{2, i} \lambda_{i}^{2}}{2}\left(E_{1 i}\right)^{2}\left[\frac{\left(1-\theta_{1, i}\right)^{2}}{P_{2, i}}\right]+h_{4, i} \varphi_{i} \lambda_{i}\left(E_{1 i}\right)+\frac{h_{1, i} \lambda_{i}{ }^{2}}{2}\left(E_{0 i}\right)^{2} E_{i P}\right\} \\
& \frac{d^{2} E\left[T C U\left(T_{\mathrm{A}}\right)\right]}{d T_{\mathrm{A}}{ }^{2}}=\frac{2\left[\left(1+\alpha_{2,0}\right) K_{0}\right]}{T_{\mathrm{A}}{ }^{3}}+\sum_{i=1}^{L}\left(\frac{2 K_{i}}{T_{\mathrm{A}}{ }^{3}}\right)>0
\end{aligned}
$$


In Eq. (30), because the setup costs $K_{0}$ and $K_{i}, \alpha_{2,0}$, and the cycle length $T_{\mathrm{A}}$ are all positive, thus, $E\left[T C U\left(T_{\mathrm{A}}\right)\right]$ is convex. It follows that by setting Eq. $(29)=0$, the following $T_{\mathrm{A}} *$ can be derived:

$$
T_{\mathrm{A}}^{*}=\sqrt{\left\{\begin{array}{l}
{\left[\left(1+\alpha_{2,0}\right) K_{0}\right]+\sum_{i=1}^{L} K_{i}} \\
\left\{\frac{h_{2,0}}{2}\right)\left\{\frac{\left[\lambda_{0}\left(1-\theta_{1,0}\right)\right]^{2}}{\left(1+\alpha_{1,0}\right) P_{2,0}}\right\} E_{10}{ }^{2}+\left(\frac{h_{1,0}}{2}\right)\left(\lambda_{0}\right)^{2} E_{0 P} E_{00}{ }^{2}+h_{4,0} \varphi_{0} \lambda_{0} E_{10} \\
\left.+h_{1,0} \sum_{i=1}^{L}\left\{\frac{\lambda_{i}^{2}}{2 P_{1, \mathrm{i}}} E_{0 i}{ }^{2}+\left[\left(\frac{\lambda_{i}}{P_{1, \mathrm{i}}} E_{0 i}+\frac{\lambda_{i}\left(1-\theta_{1, i}\right)}{P_{2, i}} E_{1 i}\right)\left(\sum_{i=1}^{L}\left(\lambda_{i} E_{0 i}\right)-\sum_{j=1}^{i}\left(\lambda_{j} E_{0 j}\right)\right)\right]\right\}\right\} \\
+\sum_{i=1}^{L}\left\{\frac{h_{1, i} \lambda_{i}^{2}}{2}\left(E_{0 i}\right)^{2} E_{i P}+\frac{h_{2, i} \lambda_{i}^{2}}{2}\left(E_{1 i}\right)^{2}\left[\frac{\left(1-\theta_{1, i}\right)^{2}}{P_{2, i}}\right]+h_{4, i} \varphi_{i} \lambda_{i}\left(E_{1 i}\right)\right\}
\end{array}\right.}
$$

Lastly, if the sum of the setup times $S_{\mathrm{i}}$ is larger than the idle time (see Fig. 1) in $T_{\mathrm{A}}{ }^{*}$, then, we should further compute the $T_{\min }$ (as mentioned by Nahmias (2009)) and choose the maximum of $\left(T_{\mathrm{A}} *, T_{\min }\right)$ as the final cycle length solution for this multi-item postponement problem to ensure that there is sufficient time for setup, manufacturing, and rework in both stages.

\subsection{Prerequisite condition of this multi-item postponement model}

The prerequisite condition (i.e., Eqs. (32) and (33)) must hold to ensure the machine has enough capacity to manufacture and rework all finished items and common parts in this multi-item postponement model (Nahmias, 2009).

$$
\begin{aligned}
& \left(\sum_{i=1}^{L}\left(t_{1, i}+t_{2, i}\right)+\left(t_{1,0}+t_{2,0}\right)\right)<T_{\mathrm{A}} \text { or } \\
& {\left[\sum_{i=1}^{L} Q_{i}\left(\frac{1}{P_{1, i}}+\frac{\left(1-\theta_{1, i}\right) E\left[x_{i}\right]}{P_{2, i}}\right)+Q_{0}\left(\frac{1}{P_{T 1,0}}+\frac{\left(1-\theta_{1,0}\right) E\left[x_{0}\right]}{P_{T 2,0}}\right)\right]<T_{\mathrm{A}}}
\end{aligned}
$$

or

$$
\left\{\sum_{i=1}^{L}\left(\frac{\lambda_{i}}{\left[1-\varphi_{i} E\left[x_{i}\right]\right]}\right)\left[\frac{1}{P_{1, i}}+\frac{\left(1-\theta_{1, i}\right) E\left[x_{i}\right]}{P_{2, i}}\right]+\left(\frac{\lambda_{0}}{\left[1-\varphi_{0} E\left[x_{0}\right]\right]}\right)\left(\frac{1}{P_{T 1,0}}+\frac{\left(1-\theta_{1,0}\right) E\left[x_{0}\right]}{P_{T 2,0}}\right)\right\}<1
$$

\section{Numerical illustration \& discussion}

Consider that five customized products that have common parts associated with them are to be made using a twostage postponement fabrication scheme. To accelerate the manufacturing process of all common parts in stage 1 , an overtime strategy is implemented. For each end product the annual demand and production rates along with their cost parameters and defective, scrap, and rework rates are given in the following Tables 1, 2(a), and 2(b). Whereas the parameters' values for the same problem using a single-stage manufacturing scheme are exhibited in Tables B-1(a) \& B-1(b) (see Appendix B).

Table 1

The assumed variables' values in stage 1 of this study

\begin{tabular}{cccccccccc}
\hline$P_{1,0}$ & $K_{0}$ & $C_{0}$ & $C_{\mathrm{S}, 0}$ & $h_{1,0}$ & $\lambda_{0}$ & $\alpha_{1,0}$ & $\alpha_{2,0}$ & $\gamma$ & $\gamma$ \\
120000 & $\$ 8500$ & $\$ 40$ & $\$ 10$ & $\$ 8$ & 17406 & 0.5 & 0.1 & 0.5 & 0.5 \\
\hline$P_{2,0}$ & $x_{0}$ & $C_{\mathrm{R}, 0}$ & $\mathrm{i}_{0}$ & $h_{2,0}$ & $h_{4,0}$ & $\alpha_{3,0}$ & $\varphi_{0}$ & $\theta_{1,0}$ & $\theta_{2,0}$ \\
96000 & $2.5 \%$ & $\$ 25$ & 0.2 & $\$ 8$ & $\$ 1$ & 0.25 & 0.09 & 0.05 & 0.05 \\
\hline
\end{tabular}


Table 2(a)

The values of relevant parameters in stage 2 of this study

\begin{tabular}{ccccccccc}
\hline Product $i$ & $P_{1, i}$ & $P_{2, i}$ & $K_{i}$ & $\lambda_{i}$ & $C_{i}$ & $h_{1, i}$ & $h_{2, i}$ & $h_{4, i}$ \\
\hline 1 & 112258 & 89806 & $\$ 8500$ & 3000 & $\$ 40$ & $\$ 16$ & $\$ 16$ & $\$ 3$ \\
2 & 116066 & 92852 & $\$ 9000$ & 3200 & $\$ 50$ & $\$ 18$ & $\$ 18$ & $\$ 5$ \\
3 & 120000 & 96000 & $\$ 9500$ & 3400 & $\$ 60$ & $\$ 20$ & $\$ 20$ & $\$ 7$ \\
4 & 124068 & 99254 & $\$ 10000$ & 3600 & $\$ 70$ & $\$ 22$ & $\$ 22$ & $\$ 10$ \\
5 & 128276 & 102621 & $\$ 10500$ & 3800 & $\$ 80$ & $\$ 24$ & $\$ 24$ & $\$ 13$ \\
\hline
\end{tabular}

Table 2(b)

The values of relevant parameters in stage 2 of this study

\begin{tabular}{ccccccc}
\hline Product $i$ & $x_{i}$ & $C_{\mathrm{R}, i}$ & $C_{\mathrm{S}, i}$ & $\theta_{1, i}$ & $\theta_{2, i}$ & $\varphi_{i}$ \\
\hline 1 & $2.5 \%$ & $\$ 25$ & $\$ 10$ & 0.05 & 0.05 & 0.09 \\
2 & $7.5 \%$ & $\$ 30$ & $\$ 15$ & 0.09 & 0.09 & 0.18 \\
3 & $12.5 \%$ & $\$ 35$ & $\$ 20$ & 0.15 & 0.15 & 0.27 \\
4 & $17.5 \%$ & $\$ 40$ & $\$ 25$ & 0.20 & 0.20 & 0.36 \\
5 & $22.5 \%$ & $\$ 45$ & $\$ 30$ & 0.26 & 0.26 & 0.45 \\
\hline
\end{tabular}

Apply Eq. (31) and Eq. (28), one finds that the optimal $T_{\mathrm{A}}^{*}=0.5383$ (year) and $E\left[T C U\left(T_{\mathrm{A}}^{*}\right)\right]=$ $\$ 2,204,939$. The convexity of $E\left[T C U\left(T_{\mathrm{A}}\right)\right]$ is explicitly illustrated in Fig. 5. It shows the expected system cost rises knowingly in both directions as the common cycle length deviates from $T_{\mathrm{A}}{ }^{*}$.

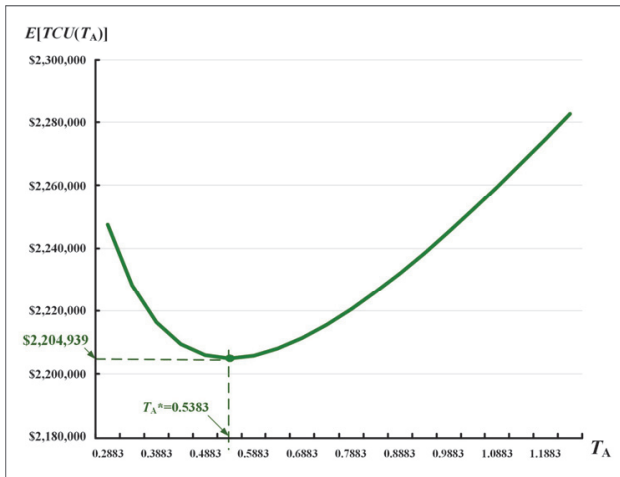

Fig. 5. The convexity of $E\left[T C U\left(T_{\mathrm{A}}\right)\right]$

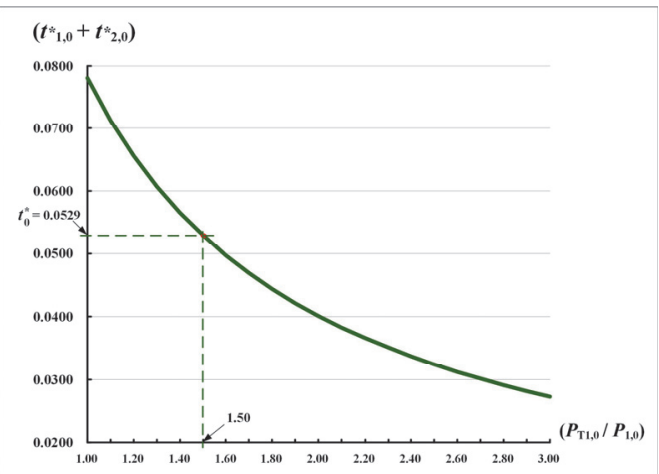

Fig. 6. The impact of overtime factor on the optimal sum of uptime and rework time $\left(t_{0} *\right)$ in stage 1

\subsection{The overtime impact on machine utilization and system cost}

In stage 1, we adopt an overtime policy in the production and rework of the common parts, its impact on the optimal sum of uptime and rework time $\left(t_{0} *\right)$ are analyzed and exhibited in Fig. 6 . It specifies that due to the overtime implementation (i.e., 1.5 times the regular shift) the optimal uptime plus rework time in stage one, $t_{0}^{*}$ declines $32.2 \%$ (i.e., from 0.0780 to 0.0529 (years)). Further analysis shows that the overall utilization for the proposed multi-item postponement model is 0.2521 (see Fig. 7). It declines by $16.3 \%$ from 0.3012 due to the implementation of overtime policy (at 1.5 times the regular shift).

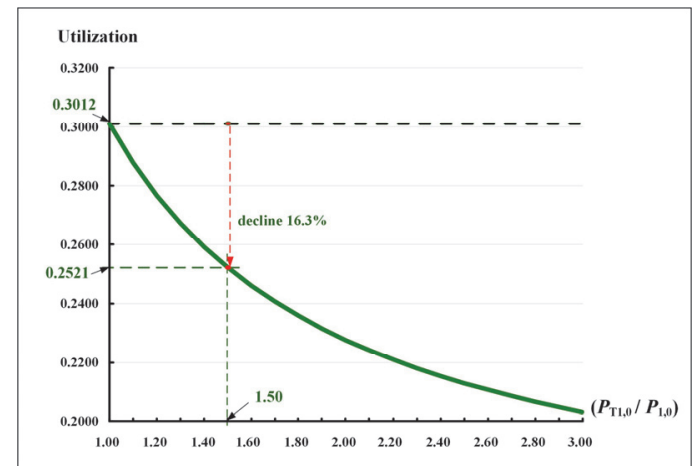

Fig. 7. The influence of overtime factor on overall machine utilization for this postponement model

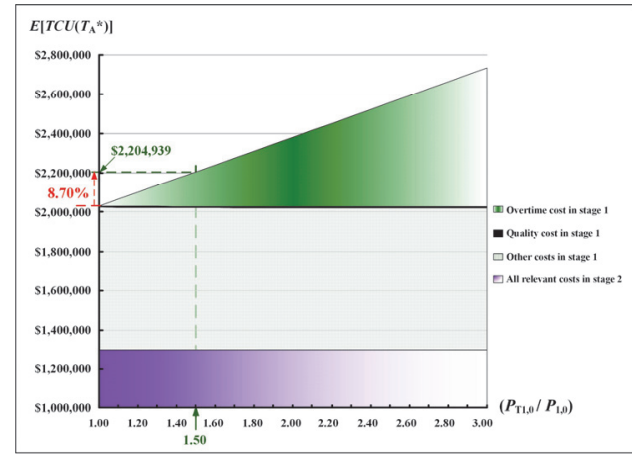

Fig. 8. The effect of overtime factor on different system cost contributors 
Fig. 8 depicts the effect of overtime factor on different system cost contributors to the system. It reveals that total system cost $E\left[T C U\left(T_{\mathrm{A}}{ }^{*}\right)\right]$ increases from $\$ 2,028,449$ to $\$ 2,204,939$ (i.e., it rises $8.64 \%$ ) as we set the overtime factor $\left(P_{\mathrm{T} 1,0} / P_{1,0}\right)$ at 1.5 ; and as the ratio $\left(P_{\mathrm{T} 1,0} / P_{1,0}\right)$ goes higher, $E\left[T C U\left(T_{\mathrm{A}} *\right)\right]$ increases significantly.

\subsection{Analysis of different relationship between common part's value and its completion rate}

We further demonstrate (see Fig. 9) that our postponement model can analyze different relationships between the value of the common part $(\delta)$ and its completion rate $(\gamma)$. For instance, if the completion rate of common part $\gamma=50 \%$ as compared with its finished product, then for its value that is linearly relating to $\gamma$, it is $50 \%$ (i.e., $\delta$ ) of the unit fabrication cost. In real applications, this may not always be the case, sometimes, a nonlinear relationship can better explain the real-life situation. Our model can analyze any specific relationship between $\delta$ and $\gamma$ as exhibited in Fig. 9.

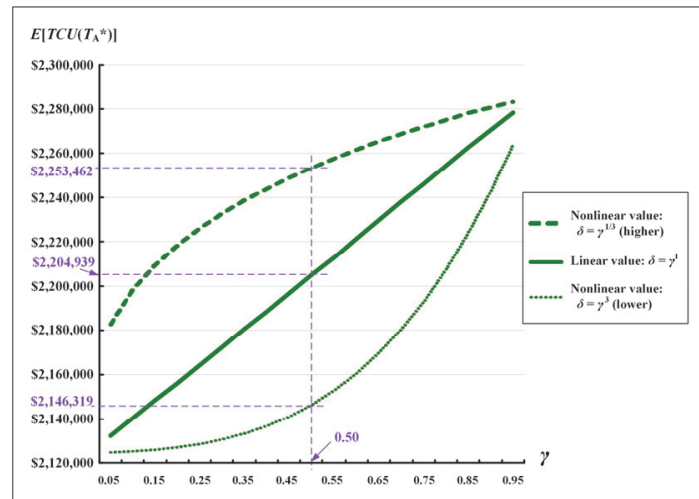

Fig. 9. The effect of different relationships between $\delta$ and $\gamma$ on $E\left[T C U\left(T_{\mathrm{A}}{ }^{*}\right)\right]$

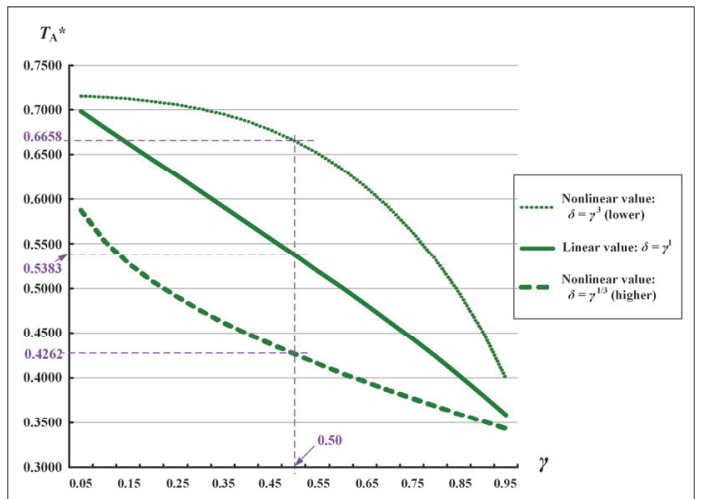

Fig. 10. The impact of different relationships between $\delta$ and $\gamma$ on $T_{\mathrm{A}}$ *

Fig. 10 illustrate the impact of different relationships between $\delta$ and $\gamma$ on $T_{\mathrm{A}} *$. It reveals that for any particular relationships between $\delta$ and $\gamma$, our proposed model is able to find the optimal common cycle times, respectively.

\subsection{The collective influence of different factors on $E\left[T C U\left(T_{\mathrm{A}}^{*}\right)\right]$ and $t_{0}{ }^{*}$}

The collective influence of different factors on the optimal system cost and common cycle time can also be explicitly explored by our model. For instance, Fig. 11 depicts the analytical result of the collective influence of changes in average defective and scrap rates on $E\left[T C U\left(T_{\mathrm{A}}{ }^{*}\right)\right]$. It shows that as both average defective and scrap rates go up, $E\left[T C U\left(T_{\mathrm{A}}{ }^{*}\right)\right]$ increases knowingly; and the average defective rate has more impact on $E\left[T C U\left(T_{\mathrm{A}}^{*}\right)\right]$ than that of average scrap rate.

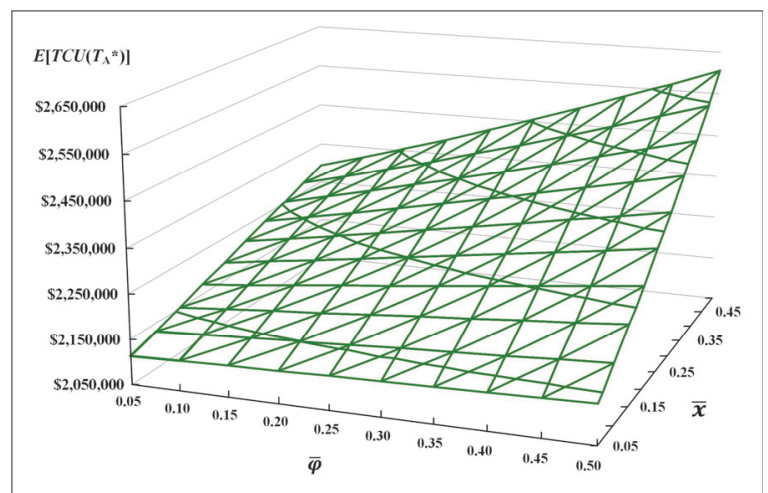

Fig. 11. The collective influence of changes in average defective and scrap rates on $E\left[T C U\left(T_{\mathrm{A}}{ }^{*}\right)\right]$

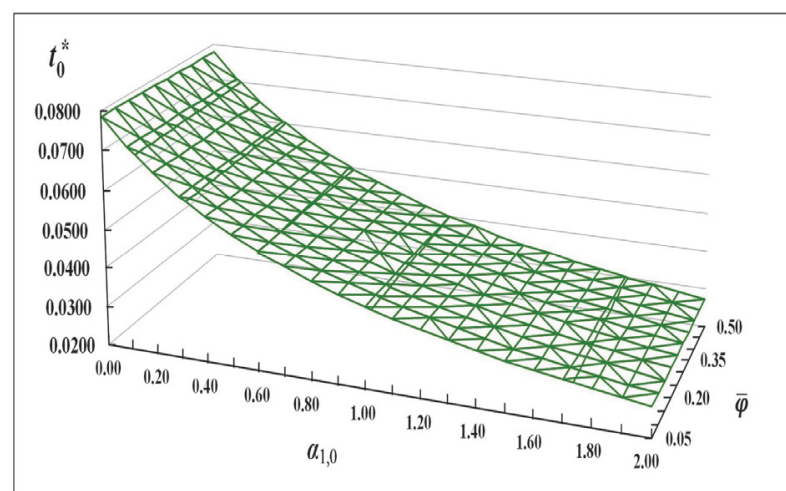

Fig. 12. The collective impact of differences in overtime factor and average scrap rate on $t_{0} *$ 
Further, Fig. 12 illustrates the analytical outcome of the collective impact of differences in overtime factor and average scrap rate on the optimal sum of uptime and rework time $\left(t_{0}{ }^{*}\right)$ in stage 1 . It reconfirms the result shown in Fig. 6 and reveals that the overtime factor has more influence on the production and rework times for the common parts than that of the average scrap rate.

\subsection{Comparison and discussion}

The comparison of the utilization and total system costs obtained from this study and an existing postponement model without overtime (Chiu et al., 2016) is exhibited in Fig. 13. Due to the overtime implementation, the utilization (i.e., $\left(t_{0}{ }^{*}+t_{\mathrm{i}}{ }^{*}\right) / T_{\mathrm{A}}{ }^{*}$ ) of this study is 0.2521 which is $16.3 \%$ (also refer to Fig. 7) lower than that of an existing postponement model without overtime policy in stage 1 (Chiu et al., 2016); at the price of $8.70 \%$ increase in costs (i.e., rising from $\$ 2,028,449$ to $\$ 2,204,939$ (also refer to Fig. 8).
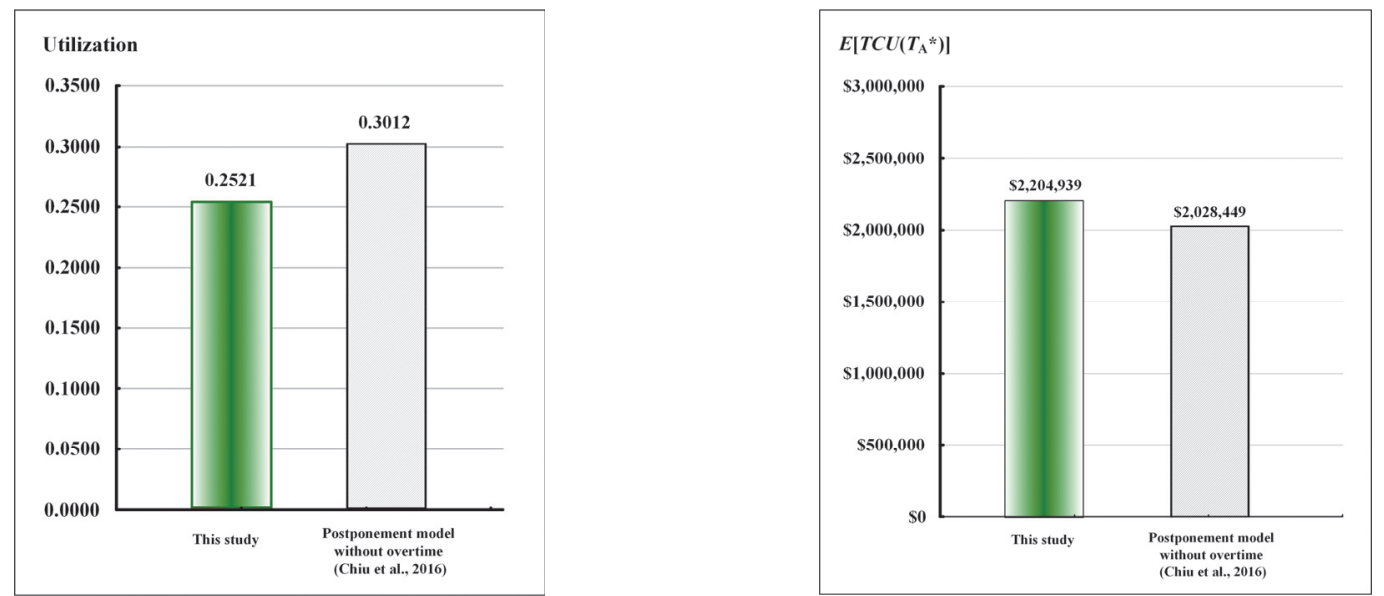

Fig. 13. Comparison of the utilization and $E\left[T C U\left(T_{\mathrm{A}}^{*}\right)\right]$ of this study with an existing model

\section{Conclusions}

This work explicitly has developed a two-stage postponement model for multi-item replenishment decision featuring commonality, implementation of overtime strategy on the fabrication of common parts, product quality reassurance in both stages, and continuous issuing discipline for the finished products. Formulation and mathematical derivations (subsections 3 and 4) enable us to find the total system costs $E\left[T C U\left(T_{\mathrm{A}}\right)\right]$. Using the differential calculus we arrive at the optimal replenishment cycle time decision $T_{\mathrm{A}} *$. A numerical illustration (subsection 5) is offered to show the applicability and capability of our model. It can reveal (i) the individual impact of the system features (e.g., the overtime factor, commonality in terms of the common part completion rate and its relative value, and the issues pertaining to scrap/rework) on the optimal decision, utilization, and the total system cost (refer to Figs. 5 to 10); and (ii) the collective influence of system features on the highlighted problem (see Figs. 11 to 12). This proposed decision-support model helps production managers achieve the operating goals of lowering total system expenses and shortening the length of the fabrication cycle. For future study, one may explore the influence of implementing common parts outsourcing policy on the operating decision of the same problem.

\section{Acknowledgments}

Authors show sincere gratitude to the Ministry of Science and Technology of Taiwan for sponsoring this research (grant\#: MOST 107-2410-H-324-002). 


\section{References}

Abashar, M.E.E. (2018). Ultra-clean hydrogen production by ammonia decomposition. Journal of King Saud University - Engineering Sciences, 30(1), 2-11.

Alfredsson, P. (1997). Optimization of multi-echelon repairable item inventory systems with simultaneous location of repair facilities. European Journal of Operational Research, 99(3), 584-595.

Akkan, C. (1996). Overtime scheduling: an application in finite-capacity real-time scheduling. Journal of the Operational Research Society, 47, 1137-1149.

Ahranjani, L.Z., \& Matin, R.K. (2018). Technical measure of capacity utilization in two-stage production systems: A data envelopment analysis approach. Economic Computation and Economic Cybernetics Studies and Research, 52(2), 235-249.

Aringhieri, R., Duma, D., \& Fragnelli, V. (2018). Modeling the rational behavior of individuals on an ecommerce system. Operations Research Perspectives, 5, 22-31.

Chiu, S.W., Kuo, J-S., Chiu, V., \& Chiu, Y-S.P. (2016). Cost minimization for a multi-product fabricationdistribution problem with commonality, postponement, and quality assurance. Mathematical and Computational Applications, 21(3), Art. No. 38, 1-17.

Chiu, Y-S.P., Lin, H-D., Wu, M-F., \& Chiu, S.W. (2018a). Alternative fabrication scheme to study effects of rework of nonconforming products and delayed differentiation on a multiproduct supply-chain system. International Journal of Industrial Engineering Computations, 9(2), 235-248.

Chiu, S.W., Wu, H.Y., Chiu, Y.-S.P., \& Hwang, M.-H. (2018b). Exploration of finite production rate model with overtime and rework of nonconforming products. Journal of King Saud University Engineering Sciences, 30(3), 224-231.

Chiu, S.W., Lin, H.-D., Chou, C.-L., \& Chiu, Y.-S.P. (2018c). Mathematical modeling for exploring the effects of overtime option, rework, and discontinuous inventory issuing policy on EMQ model. International Journal of Industrial Engineering Computations, 9(4), 479-490.

Chiu, S.W., Kuo, J-S., Chiu, Y-S.P., \& Chang, H-H. (2019a). Production and distribution decisions for a multi-product system with component commonality, postponement strategy and quality assurance using a two-machine scheme. Jordan Journal of Mechanical \& Industrial Engineering, 13(2), 105115.

Chiu, S.W., Huang, Y-J., Chiu, Y-S.P., \& Chiu, T. (2019b). Satisfying multiproduct demand with a FPRbased inventory system featuring expedited rate and scraps. International Journal of Industrial Engineering Computations, 10(3), 443-452.

Iqbal, A., Ahmad, S.A., \& Ojasvi (2019). Appropriate selections of distillation column control variable to improve integrating material recycle response. Journal of King Saud University - Engineering Sciences, 31(2), 106-113.

Istotskiy, V., \& Protasev, V. (2019). Design and manufacture of hob mills for the formation of straight slots using the principles of screw backing. International Journal of Mathematical, Engineering and Management Sciences, 4(4), 936-945.

Jirjahn, U. (2008). On the determinants of shift work and overtime work: Evidence from German establishment data. British Journal of Industrial Relations, 46(1), 133-168.

Khanna, A., Gautam, P., \& Jaggi, C.K. (2017). Inventory modeling for deteriorating imperfect quality items with selling price dependent demand and shortage backordering under credit financing. International Journal of Mathematical, Engineering and Management Sciences, 2(2), 110-124.

Ko, J., \& Jack Hu, S. (2008). Balancing of manufacturing systems with complex configurations for delayed product differentiation. International Journal of Production Research, 46(15), 4285-4308.

Lagodimos, A.G., \& Mihiotis, A.N. (2006). Overtime vs. regular shift planning decisions in packing shops. International Journal of Production Economics, 101(2), 246-258.

Larkin, E.V., \& Privalov, A.N. (2019). Engineering method of fault -tolerant system simulations. Journal of Applied Engineering Science, 17(3), 295-303.

MohanDas, C.D., Ayyanar, A., Susaiyappan, S., \& Kalimuthu, R. (2017). Analysis of the effects of fabrication parameters on the mechanical properties of Areca fine fiber-reinforced phenol formaldehyde composite using Taguchi technique. Journal of Applied Research and Technology, 15 (4), 365-370.

Nahmias, S. (2009). Production \& Operations Analysis. McGraw-Hill Inc. New York. 
Noman, M.A., Nasr, E.S.A., Al-Shayea, A., \& Kaid, H. (2019). Overview of predictive condition based maintenance research using bibliometric indicators. Journal of King Saud University - Engineering Sciences, 31(4), 355-367.

Oladapo, B.I., Balogun, V.A., Adeoye, A.O.M., Olubunmi, I.E., \& Afolabi, S.O. (2017). Experimental analysis of electro-pneumatic optimization of hot stamping machine control systems with on-delay timer. Journal of Applied Research and Technology, 15(4), 356-364.

Omar, Y.M., Minoufekr, M., \& Plapper, P. (2019). Business analytics in manufacturing: Current trends, challenges and pathway to market leadership. Operations Research Perspectives, 6, Art. No.100127, $1-15$.

Ortiz-Servin, J.J., Castillo, A., \& Talavera, F. (2019). A new methodology to optimize operation cycles in a bwr using heuristic techniques. Journal of Applied Research and Technology, 17(3), 155-162.

Palos-Sanchez, P., Saura, J.R., \& Martin-Velicia, F. (2019). A study of the effects of programmatic advertising on users' concerns about privacy overtime. Journal of Business Research, 96, 61-72.

Parnianifard, A., Azfanizam, A.S., Ariffin, M.K.A., \& Ismail, M.I.S. (2019). Trade-off in robustness, cost and performance by a multi-objective robust production optimization method. International Journal of Industrial Engineering Computations, 10(1), 133-148.

Pearce, A., Pons, D., \& Neitzert, T. (2018). Implementing lean - outcomes from SME case studies. Operations Research Perspectives, 5, 94-104.

Rao, A.S., \& Singh, A.K. (2018). Failure analysis of stainless steel lanyard wire rope. Journal of Applied Research and Technology, 16(1), 35-40.

Reimann, M. (2012). Accurate response by postponement, European Journal of Operational Research, 220(3), 619-628.

Roul, J.N., Maity, K., Kar, S., \& Maiti, M. (2015). Multi-item reliability dependent imperfect production inventory optimal control models with dynamic demand under uncertain resource constraint. International Journal of Production Research 53(16), 4993-5016.

Sheikh, S., Komaki, G.M., Kayvanfar, V., \& Teymourian, E. (2019). Multi-Stage assembly flow shop with setup time and release time. Operations Research Perspectives, 6 (2019), Art. No. 100111, 1-15.

Taş, D., Gendreau, M., Jabali, O., \& Jans, R. (2019). A capacitated lot sizing problem with stochastic setup times and overtime. European Journal of Operational Research, 273 (1), 146-159.

Van Mieghem, J.A., \& Dada, M. (1999). Price versus production postponement: capacity and competition. Management Science, 45(12), 1631-1649.

Van Mieghem, J.A. (1999). Coordinating investment, production and subcontracting. Management Science, 45, 954-971.

Wenbin, Z., Frenkel, I., Guixiang, S., Bolvashenkov, I., Kammermann, J., Herzog, H.-G., \& Khvatskin, L. (2019). Markov reward approach and reliability associated cost model for machine tools maintenance-planning optimization. International Journal of Mathematical, Engineering and Management Sciences, 4(4), 824-840.

Yu, S.B., \& Efstathiou, J. (2006). Complexity in rework cells: Theory, analysis and comparison. Journal of the Operational Research Society, 57(5), 593-602.

Zinn, W. (1990). Developing heuristics to estimate the impact of postponement on safety stock. The International Journal of Logistics Management, 1(2), 11-16.

\section{Appendix - A}

Details for the derivations of Eq. (28).

$E\left[T C U\left(T_{\mathrm{A}}\right)\right]$, the expected system cost per unit time can be derived by the following steps: (A) apply the expected values $E\left[x_{0}\right]$ and $E\left[x_{i}\right]$ to cope with the randomness of the nonconforming common parts and end product $i$, respectively; (B) substitute $Q_{i}$ with $T_{\mathrm{A}}$ (for $i=0,1,2, \ldots, L$; refer to Eqs. (7) and (15)); (C) substitute Eqs. (1) to (26) in Eq. (27) and calculating $E\left[T C\left(T_{\mathrm{A}}\right)\right] / E\left[T_{\mathrm{A}}\right]$. With extra derivation efforts, $E\left[\operatorname{TCU}\left(T_{\mathrm{A}}\right)\right]$ is obtained as shown in Eq. (A-1). 


$$
\begin{aligned}
& E\left[\operatorname{TCU}\left(T_{\mathrm{A}}\right)\right]= \\
& {\left[\left[\left(1+\alpha_{3,0}\right) C_{0}\right]\left(\frac{\lambda_{0}}{1-\varphi_{0} E\left[x_{0}\right]}\right)+\frac{\left[\left(1+\alpha_{2,0}\right) K_{0}\right]}{T_{A}}+\left[\left(1+\alpha_{3,0}\right) C_{R}\right]\left[E\left[x_{0}\right]\left(1-\theta_{1,0}\right)\left(\frac{\lambda_{0}}{1-\varphi_{0} E\left[x_{0}\right]}\right)\right]\right.} \\
& +C_{\mathrm{S}, 0}\left[E\left[x_{0}\right] \varphi_{0}\left(\frac{\lambda_{0}}{1-\varphi_{0} E\left[x_{0}\right]}\right)\right]+\left(\frac{h_{2,0}}{2}\right)\left\{\left(\frac{\lambda_{0}^{2} T_{A}}{1-\varphi_{0}^{2} E\left[x_{0}\right]^{2}}\right)\left[\left(\frac{E\left[x_{0}\right]^{2}\left(1-\theta_{1,0}\right)^{2}}{\left(1+\alpha_{1,0}\right) P_{2,0}}\right)\right]\right\}+h_{4,0} \varphi_{0} E\left[x_{0}\right]\left(\frac{\lambda_{0} T_{A}}{1-\varphi_{0} E\left[x_{0}\right]}\right) \\
& \left\{+\left(\frac{h_{1,0}}{2}\right)\left(\frac{\lambda_{0}^{2} T_{A}}{1-\varphi_{0}^{2} E\left[x_{0}\right]^{2}}\right)\left[\frac{1}{\left(1+\alpha_{1,0}\right) P_{1,0}}+\frac{2 E\left[x_{0}\right]\left(1-\theta_{1,0}\right)}{\left(1+\alpha_{1,0}\right) P_{2,0}}-\frac{E\left[x_{0}\right]^{2}\left(1-\theta_{1,0}\right)\left(1+\varphi_{0}\right)}{\left(1+\alpha_{1,0}\right) P_{2,0}}\right]+h_{1,0} \sum_{i=1}^{L}\left\{\frac{\lambda_{i}^{2} T_{A}}{2 P_{1, i}}\left(\frac{1}{1-\varphi_{i} E\left[x_{i}\right]}\right)^{2}\right\}\right. \\
& +h_{1,0} \sum_{i=1}^{L}\left[\frac{\lambda_{i} T_{A}}{P_{1, i}}\left(\frac{1}{1-\varphi_{i} E\left[x_{i}\right]}\right) \sum_{i=1}^{L} \frac{\lambda_{i}}{\left(1-\varphi_{i} E\left[x_{i}\right]\right)}+\frac{\lambda_{i} T_{A} E\left[x_{i}\right]\left(1-\theta_{1, i}\right)}{P_{2, i}}\left(\frac{1}{1-\varphi_{i} E\left[x_{i}\right]}\right) \sum_{i=1}^{L} \frac{\lambda_{i}}{\left(1-\varphi_{i} E\left[x_{i}\right]\right)}\right] \\
& +h_{1,0} \sum_{i=1}^{L}\left[-\frac{\lambda_{i} T_{A}}{P_{1, \mathrm{i}}}\left(\frac{1}{1-\varphi_{i} E\left[x_{i}\right]}\right) \sum_{j=1}^{i} \frac{\lambda_{j}}{\left(1-\varphi_{j} E\left[x_{j}\right]\right)}-\frac{\lambda_{i} T_{A} E\left[x_{i}\right]\left(1-\theta_{1, i}\right)}{P_{2, i}}\left(\frac{1}{1-\varphi_{i} E\left[x_{i}\right]}\right) \sum_{j=1}^{i} \frac{\lambda_{j}}{\left(1-\varphi_{j} E\left[x_{j}\right]\right)}\right] \\
& \int C_{i} \lambda_{i} \frac{1}{\left(1-E\left[x_{i}\right] \varphi_{i}\right)}+\frac{K_{i}}{T_{A}}+C_{R, i} \lambda_{i}\left[\frac{E\left[x_{i}\right]\left(1-\theta_{1, i}\right)}{1-E\left[x_{i}\right] \varphi_{i}}\right]+\frac{h_{2, i}}{2} \frac{\lambda_{i}^{2} T_{A}}{\left(1-E\left[x_{i}\right] \varphi_{i}\right)^{2}}\left[\frac{E\left[x_{i}\right]^{2}\left(1-\theta_{1, i}\right)^{2}}{P_{2, i}}\right] \\
& +\sum_{i=1}^{L}\left\{+h_{4, i} \varphi_{i} \lambda_{i} T_{A}\left(\frac{E\left[x_{i}\right]}{1-E\left[x_{i}\right] \varphi_{i}}\right)+C_{\mathrm{S}, i} \lambda_{i}\left(\frac{E\left[x_{i}\right] \varphi_{i}}{1-E\left[x_{i}\right] \varphi_{i}}\right)\right. \\
& \left.+\left(\frac{h_{1, i}}{2}\right) \frac{\lambda_{i}^{2} T_{A}}{\left(1-\varphi_{i} E\left[x_{i}\right]\right)^{2}}\left(\frac{1-E\left[x_{i}\right] \varphi_{i}\left(2-E\left[x_{i}\right] \varphi_{i}\right)}{\lambda_{i}}+\frac{-1+2 E\left[x_{i}\right] \varphi_{i}}{P_{1, \mathrm{i}}}+\frac{-E\left[x_{i}\right]^{2}\left(1-\varphi_{i}-\theta_{1, i}+\theta_{1, i} \varphi_{i}\right)}{P_{2, i}}\right)\right)
\end{aligned}
$$

Let $E_{00}, E_{10}, E_{0 j}, E_{0 P}, E_{i P}, E_{0 i}$, and $E_{1 i}$ denote the following:

$$
\begin{aligned}
& E_{00}=\frac{1}{\left(1-\varphi_{0} E\left[x_{0}\right]\right)} ; E_{10}=\frac{E\left[x_{0}\right]}{\left(1-\varphi_{0} E\left[x_{0}\right]\right)} ; E_{0 j}=\frac{1}{\left(1-\varphi_{j} E\left[x_{j}\right]\right)} \text { for } j=1,2, \ldots, i ; \\
& E_{0 P}=\left[\frac{1}{\left(1+\alpha_{1,0}\right) P_{1,0}}+\frac{2 E\left[x_{0}\right]\left(1-\theta_{1,0}\right)}{\left(1+\alpha_{1,0}\right) P_{2,0}}-\frac{E\left[x_{0}\right]^{2}\left(1-\theta_{1,0}\right)\left(1+\varphi_{0}\right)}{\left(1+\alpha_{1,0}\right) P_{2,0}}\right] ; \\
& E_{i P}=\left[\frac{1-E\left[x_{i}\right] \varphi_{i}\left(2-E\left[x_{i}\right] \varphi_{i}\right)}{\lambda_{i}}+\frac{-1+2 E\left[x_{i}\right] \varphi_{i}}{P_{1, i}}+\frac{-E\left[x_{i}\right]^{2}\left(1-\varphi_{i}-\theta_{1, i}+\theta_{1, i} \varphi_{i}\right)}{P_{2, i}}\right] ; \\
& E_{0 i}=\frac{1}{\left(1-\varphi_{i} E\left[x_{i}\right]\right)} \text { for } i=1,2, \ldots, L ; E_{1 i}=\frac{E\left[x_{i}\right]}{\left(1-\varphi_{i} E\left[x_{i}\right]\right)} \text { for } i=1,2, \ldots, L .
\end{aligned}
$$

Substitute Eq. (A-2) in Eq. (A-1), the following $E\left[T C U\left(T_{\mathrm{A}}\right)\right]$ is gained:

$$
\begin{aligned}
E\left[T C U\left(T_{\mathrm{A}}\right)\right]=\left\{\begin{array}{l}
\frac{\left[\left(1+\alpha_{2,0}\right) K_{0}\right]}{T_{A}}+\left[\left(1+\alpha_{3,0}\right) C_{0}\right] \lambda_{0} E_{00}+\left[\left(1+\alpha_{3,0}\right) C_{R}\right] \lambda_{0}\left(1-\theta_{1,0}\right) E_{10} \\
+C_{\mathrm{S}, 0} \varphi_{0} \lambda_{0} E_{10}+\left(\frac{h_{2,0}}{2}\right)\left\{\frac{T_{A}\left[\lambda_{0}\left(1-\theta_{1,0}\right)\right]^{2}}{\left(1+\alpha_{1,0}\right) P_{2,0}}\right\} E_{10}{ }^{2}+\left(\frac{h_{1,0}}{2}\right)\left(T_{A} \lambda_{0}{ }^{2}\right) E_{0 P} E_{00}{ }^{2} \\
+h_{1,0} \sum_{i=1}^{L}\left\{\frac{\lambda_{i}^{2} T_{A}}{2 P_{1, \mathrm{i}}} E_{0 i}{ }^{2}\right\}+h_{1,0} \sum_{i=1}^{L}\left[\frac{\lambda_{i} T_{A}}{P_{1, \mathrm{i}}} E_{0 i} \sum_{i=1}^{L} \lambda_{i} E_{0 i}+\frac{\lambda_{i} T_{A}\left(1-\theta_{1, i}\right)}{P_{2, i}} E_{1 i} \sum_{i=1}^{L} \lambda_{i} E_{0 i}\right] \\
+h_{4,0} \varphi_{0} \lambda_{0} T_{A} E_{10}+h_{1,0} \sum_{i=1}^{L}\left[-\frac{\lambda_{i} T_{A}}{P_{1, i}} E_{0 i} \sum_{j=1}^{i} \lambda_{j} E_{0 j}-\frac{\lambda_{i} T_{A}\left(1-\theta_{1, i}\right)}{P_{2, i}} E_{1 i} \sum_{j=1}^{i} \lambda_{j} E_{0 j}\right]
\end{array}\right\} \\
+\sum_{i=1}^{L}\left\{\begin{array}{l}
C_{i} \lambda_{i}\left(E_{0 i}\right)+\frac{K_{i}}{T_{A}}+C_{R, i} \lambda_{i}\left(1-\theta_{1, i}\right)\left(E_{1 i}\right)+C_{\mathrm{S}, i} \lambda_{i} \varphi_{i}\left(E_{1 i}\right) \\
+\frac{h_{2, i} \lambda_{i} T_{A} T_{A}}{2}\left(E_{1 i}\right)^{2}\left[\frac{\left(1-\theta_{1, i}\right)^{2}}{P_{2, i}}\right]+h_{4, i} \varphi_{i} \lambda_{i} T_{A}\left(E_{1 i}\right)+\frac{h_{1, i} \lambda_{i}^{2} T_{A}}{2}\left(E_{0 i}\right)^{2} E_{i P}
\end{array}\right\}
\end{aligned}
$$




\section{Appendix - B}

Table B-1(a)

The parameters' values of the same problem under a one stage production scheme

\begin{tabular}{ccccccccc}
\hline Product $i$ & $P_{1, i}$ & $P_{2, i}$ & $K_{i}$ & $\lambda_{i}$ & $C_{i}$ & $h_{1, i}$ & $h_{2, i}$ & $h_{4, i}$ \\
\hline 1 & 58000 & 46400 & $\$ 17000$ & 3000 & $\$ 80$ & $\$ 16$ & $\$ 16$ & $\$ 3$ \\
2 & 59000 & 47200 & $\$ 17500$ & 3200 & $\$ 90$ & $\$ 18$ & $\$ 18$ & $\$ 5$ \\
3 & 60000 & 48000 & $\$ 18000$ & 3400 & $\$ 100$ & $\$ 20$ & $\$ 20$ & $\$ 7$ \\
4 & 61000 & 48800 & $\$ 18500$ & 3600 & $\$ 110$ & $\$ 22$ & $\$ 22$ & $\$ 10$ \\
5 & 62000 & 49600 & $\$ 19000$ & 3800 & $\$ 120$ & $\$ 24$ & $\$ 24$ & $\$ 13$ \\
\hline
\end{tabular}

Table B-1(b)

The parameters' values of the same problem under a one stage production scheme

\begin{tabular}{ccccccc}
\hline Product $i$ & $x_{i}$ & $C_{\mathrm{R}, i}$ & $C_{\mathrm{S}, i}$ & $\theta_{1, i}$ & $\theta_{2, i}$ & $\varphi_{i}$ \\
\hline 1 & $5 \%$ & $\$ 50$ & $\$ 20$ & 0.09 & 0.09 & 0.18 \\
2 & $10 \%$ & $\$ 55$ & $\$ 25$ & 0.15 & 0.15 & 0.27 \\
3 & $15 \%$ & $\$ 60$ & $\$ 30$ & 0.20 & 0.20 & 0.36 \\
4 & $20 \%$ & $\$ 65$ & $\$ 35$ & 0.26 & 0.26 & 0.45 \\
5 & $25 \%$ & $\$ 70$ & $\$ 40$ & 0.32 & 0.32 & 0.54 \\
\hline
\end{tabular}

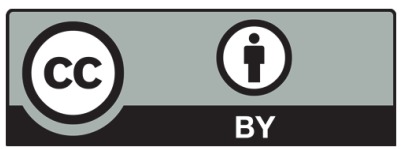

(C) 2020 by the authors; licensee Growing Science, Canada. This is an open access article distributed under the terms and conditions of the Creative Commons Attribution (CCBY) license (http://creativecommons.org/licenses/by/4.0/). 